\title{
The descriptive epidemiology of local restaurant smoking regulations in Massachusetts: an analysis of the protection of restaurant customers and workers
}

\section{Skeer, M Siegel}

See end of article for authors' affiliations

Correspondence to: Margie Skeer, MSW, Boston University School of Public Health, Social and Behavioral Sciences Department, 715 Albany Street, T2W, Boston, MA 02118 , USA; skeer@bu.edu

Received 13 September 2002. Accepted 23 March 2003
Objectives: To describe the range of restaurant smoking regulations in the 351 cities and towns in Massachusetts, and to analyse the level of protection from secondhand smoke exposure guaranteed by these regulations.

Design: We obtained the local restaurant smoking regulations for each town, analysing them in terms of the protection of restaurant workers, bar workers, and adult and youth restaurant customers.

Main outcome measure: The percentage of restaurant patrons and workers and bar workers who are protected from secondhand smoke exposure by the current smoking regulations in Massachusetts.

Results: As of June 2002, 225 towns had local restaurant smoking regulations. Of these, 69 (30.7\%) do not allow smoking in restaurants, $10(4.4 \%)$ restrict smoking to adult only restaurants, $64(28.4 \%)$ restrict smoking to enclosed, separately ventilated areas, and $82(36.4 \%)$ restrict smoking to areas that need not be enclosed and separately ventilated. Of the 174 towns that, at a minimum, restrict smoking to bar areas or separately ventilated areas, 35 (20.1\%) allow variances. Overall, 60 towns, covering only $17.7 \%$ of the population, completely ban smoking in restaurants. As a result, $81.3 \%$ of adult restaurant customers, $81.2 \%$ of youth customers, $82.3 \%$ of restaurant workers, and $87.0 \%$ of bar workers are not guaranteed protection from secondhand smoke in restaurants.

Conclusions: Despite the widespread adoption of local restaurant smoking regulations in Massachusetts, the majority of restaurant customers and workers remain unprotected from secondhand smoke exposure. In light of this, public health practitioners must stop compromising the protection of customers and workers from secondhand smoke exposure in restaurants.
$\mathrm{T}$ he detrimental health effects of secondhand smoke, including the effects of workplace exposure, have been well documented.$^{1-4}$ Restaurants and bars represent workplaces with the least protection from secondhand smoke ${ }^{56}$ and one of the highest levels of exposure. ${ }^{7-15}$ To protect restaurant and bar patrons and employees, many communities have adopted regulations restricting smoking in these establishments. ${ }^{16-21}$ As of July 2002, 947 US communities had adopted regulations restricting smoking in restaurants. ${ }^{20}$ In Massachusetts alone, it has been reported that as of 2000, 102 of the 351 cities and towns, covering $45 \%$ of the population, had adopted complete restaurant smoking bans. ${ }^{22}$

Communities have taken a range of approaches to restrict smoking in restaurants and bars, both in terms of the degree of smoking restriction and the types of establishments, and areas within these establishments, that are regulated. ${ }^{17}{ }^{23-28}$ For example, restrictions range from simply requiring designated smoking areas to restricting smoking to enclosed, separately ventilated (ESV) areas to complete smoking bans. ${ }^{172325-28}$ There are also gradations in the areas within establishments that are subject to regulation, such as restaurant dining areas, bar areas within restaurants, and free-standing bars. ${ }^{23}{ }^{25-29}$ Additionally, provisions exist that can create loopholes in these policies, such as allowing variances from regulations and exemptions for various situations (for example, exclusions based on number of seats, age of clientele, ventilation provided, and time of day). Because of the myriad provisions, including "loopholes", in local restaurant smoking regulations, it is not meaningful to assess the actual strength of these regulations without specifying the extent to which the regulation guarantees that patrons and workers will not be exposed to secondhand smoke.
Although a number of reports have described the prevalence and nature of local restaurant smoking regulations, ${ }^{17}{ }^{19-22} 2628{ }^{30}$ none provide a comprehensive analysis of all the provisions of each regulation and an assessment of how the totality of each regulation (interpreted in its entirety) relates to the degree of actual protection from secondhand smoke that the regulation guarantees. Several studies have reported the number of local restaurant smoking regulations in the USA or in various states. ${ }^{17-22} 262830$ While five of these studies ${ }^{17-20} 22$ report whether the policies completely ban smoking in restaurants, and three ${ }^{19} 2026$ separate out policies that cover free-standing bars, only one ${ }^{20}$ identifies regulations that allow smoking in separately ventilated areas, and only one ${ }^{26}$ reports on whether local policies include variance provisions.

Given the widespread prevalence of local restaurant smoking policies in the USA, it is surprising that we presently have very little understanding of the level of public health protection that is afforded by these policies. In the absence of any study that accounts for all regulation provisions (including exemptions and variances), regulations that have previously been termed "smoke-free" may, in practice, not actually require all restaurants to be "smoke-free". In essence, the existing literature leaves the definition of "smoke-free" restaurants up to interpretation and fails to tie the term conceptually to public health.

In this article, we describe and analyse the local restaurant smoking regulations in the 351 towns and cities in Massachusetts. Our objectives are: ( 1 ) to describe the range of restaurant smoking regulations, including all relevant provisions that would be expected to impact the actual public health protection provided by the regulation; and (2) to analyse the level of protection from secondhand smoke exposure guaranteed by these local regulations (considering restaurant 
customers and employees, and adult and youth patrons, separately) and to compare these findings to previous measures of local restaurant smoking regulations in Massachusetts.

\section{METHODS \\ Data collection}

We obtained the local restaurant smoking regulation for each of the 351 cities and towns in Massachusetts. While different policies exist that regulate smoking locally (that is, ordinances enacted by city or town councils, regulations promulgated by local boards of health, bylaws passed by voters), the term regulation will be used in this paper to refer to all such policies. We cross referenced the information obtained from the Massachusetts Department of Public Health, which maintained copies of restaurant smoking regulations, with three other databases that track local restaurant smoking regulations in Massachusetts, those maintained by the Massachusetts Municipal Association, ${ }^{31}$ Americans for Nonsmokers' Rights, ${ }^{20}$ and Bartosch and Pope. ${ }^{26-28}$ If any discrepancy existed, we obtained a hard copy of the current regulation. We revised the database to incorporate any further corrections received by local tobacco control programme personnel and local board of health contact persons in the state. This article reflects the status of regulations as of 15 June 2002.

\section{Data extraction}

For each regulation, we recorded all provisions deemed relevant to the protection of restaurant customers or employees from secondhand smoke. These included the following: (1) whether smoking was allowed; restricted to designated areas; restricted to ESV areas; or prohibited in restaurant dining areas, bar areas of restaurants, and free-standing bars; (2) the maximum permitted relative seating capacity of any smoking areas; (3) whether or not the regulation required that non-smoking areas be situated so that non-smokers did not need to pass through smoking areas in order to reach their seats; (4) whether minors were allowed in the smoking areas; (5) whether or not any variance procedure was provided, and the requirements that needed to be met in order to obtain a variance; and (6) any exceptions or exemptions to the above.

\section{Regulation coding system}

Based on the data extracted for each regulation, we classified towns into one of eight categories: (0) no restaurant smoking restrictions; (1) smoking in restaurants restricted, but not to ESV areas; (2) smoking in restaurants restricted to bar areas that need not be enclosed and separately ventilated; (3) smoking allowed in restaurant dining areas, but restricted to ESV areas; (4) smoking in restaurants restricted to bar areas that are enclosed and separately ventilated; (5) smoking allowed only in adult only restaurants; (6) no smoking in restaurants, including bar areas, but smoking allowed in free-standing bars; and (7) no smoking in restaurants, including bar areas, or in free-standing bars. This coding system represents a slight modification of that developed by Chriqui et al. ${ }^{23}$ Separately, we coded whether the regulation allowed a variance.

Several regulations permitted exceptions to the smoking restrictions, but as a formality, permission in the form of a variance was required. For example, a regulation that prohibits smoking in restaurants might include an "Exceptions" section, which stipulates that if a restaurant is granted a variance, smoking would be permitted in designated smoking areas that are ESV. These exceptions were included in our coding.

We expanded on the Chriqui $e \mathrm{al}^{23}$ coding system to include three additional scenarios that were not originally accounted for. These changes included: (1) separating the code for regulations that restricted smoking to ESV areas into two distinct codes-one that reflects the restriction of smoking to designated areas in restaurant dining rooms, and one that reflects the restriction of smoking to ESV bar areas of restaurants; (2) adding a code for regulations that restricted smoking to bar areas of restaurants without requiring separate ventilation, because a substantial number of restaurants that do not have bar areas would therefore be smoke-free; and (3) creating a code for regulations that allow smoking in adult only restaurants, a provision that would protect youth. These additions to the Chriqui et al coding system made our coding system mutually exclusive.

To test inter-rater reliability of this coding system, the authors independently coded 100 out of the 225 regulations. Upon comparison, the authors agreed on 95 of the regulations (Cronbach coefficient $\alpha=0.98$ ). The five regulations that were discrepant resulted from ambiguous language, in which the meaning of the regulation could be interpreted in two distinct ways.

\section{Main outcome measures}

In order to link our analysis of the restaurant smoking regulations to the actual public health protection afforded by these policies, we developed a series of measures to assess the extent to which the policies guarantee protection from secondhand smoke. These were segmented into four groups: ( 1 ) restaurant workers; (2) bar workers; (3) adult restaurant customers; and (4) youth restaurant customers.

\section{Restaurant workers}

We classified a regulation as guaranteeing protection for restaurant workers if the regulation completely banned smoking in all restaurants, including bar areas (codes 6 and 7) and allowed no variances. Our rationale was that regulations that allow smoking in ESV areas do not protect workers who serve in those areas.

\section{Bar workers}

We classified a regulation as guaranteeing protection for bar workers if it completely banned smoking in all free-standing bars (code 7) and allowed no variances.

\section{Adult restaurant customers}

We classified a regulation as guaranteeing protection for adult restaurant customers if it prohibited smoking in restaurants or restricted smoking to ESV areas (codes 3, 4, 6, and 7), ensured that customers would not need to pass through a smoking area to reach non-smoking seating, and allowed the designated smoking area to be no larger than $25 \%$ of the overall seating capacity. Our rationale was that ESV smoking areas would protect patrons in non-smoking areas from secondhand smoke exposure, ${ }^{32}$ but that customers would not be guaranteed protection if they needed to pass through a smoking area; and that if the size of the designated smoking area exceeded the prevalence of smoking in the population (roughly $25 \%$ ), it is likely that non-smoking seating may not be available.

\section{Youth restaurant customers}

We classified a regulation as guaranteeing protection for youth restaurant customers if it: (a) prohibited smoking in restaurants (codes 6 and 7); (b) restricted smoking to ESV areas where minors were not allowed (codes 3 and 4), where customers would not need to pass through a smoking area and where the size of a smoking area could not exceed $25 \%$ of overall seating capacity; or (c) restricted smoking to adult only establishments (code 5). Our rationale for requiring that minors not be allowed in smoking areas is that while adults can choose where they sit, minors may not always be able to.

\section{Population data source}

We used town level adult and youth population data from the 2000 United States Census ${ }^{24}$ to estimate the proportion of the adult and youth population covered by the regulations. 
Table 1 Local restaurant smoking regulations in Massachusetts, as of 15 June 2002

\begin{tabular}{|c|c|c|c|c|c|}
\hline Code & Description of code & $\begin{array}{l}\text { Number of towns } \\
(n=351)\end{array}$ & $\begin{array}{l}\% \text { of } \\
\text { towns }\end{array}$ & $\begin{array}{l}\% \text { of } \\
\text { population }\end{array}$ & $\begin{array}{l}\text { Number of towns (\%) } \\
\text { with variances* } \\
n=35(20.1 \%)\end{array}$ \\
\hline 0 & No restrictions on smoking in restaurants & 126 & 35.9 & 14.2 & NA \\
\hline 1 & Smoking in restaurants restricted, but not to ESV & 51 & 14.5 & 25.3 & NA \\
\hline 2 & Smoking in restaurants restricted to non-ESV bar areas & 31 & 8.8 & 21.7 & $12(6.9 \%)$ \\
\hline 3 & Smoking in restaurants restricted to ESV areas & 21 & 6 & 7.2 & $8(4.6 \%)$ \\
\hline 4 & No smoking in restaurant dining areas & 43 & 12.3 & 10.3 & $6(3.4 \%)$ \\
\hline 5 & Smoking allowed only in adult only restaurants & 10 & 2.9 & 1.5 & $0(0.0 \%)$ \\
\hline 6 & No smoking in restaurants (including bar areas) & 17 & 4.8 & 5.2 & $2(1.1 \%)$ \\
\hline 7 & No smoking in restaurants (and bar areas) and free-standing bars & 52 & 14.8 & 14.7 & $7(4.0 \%)$ \\
\hline
\end{tabular}

*Of the 174 towns with ordinances that are coded 2 through 7.

ESV, enclosed, separately ventilated areas; NA, not applicable because variances are not relevant to towns with no or lenient ordinances.

Because there are no town level data on the number of bar and restaurant workers, we estimated that the number of bar and restaurant workers in each town is proportional to the overall town population. Since we found that there is almost a perfect correlation $(r=0.99)$ between the number of restaurants in a town and population size, this appears to be a reasonable estimation.

\section{RESULTS \\ Description of restaurant smoking regulations and provisions}

As of 15 June 2002, 225 (64.1\%) of the 351 cities and towns in Massachusetts had adopted some type of local restaurant smoking regulation (table 1). Of these 225 regulations, 69 $(30.7 \%)$ do not allow smoking in restaurants, $10(4.4 \%)$ restrict smoking to adult only restaurants, $64(28.4 \%)$ restrict smoking to ESV areas, and $82(36.4 \%)$ restrict smoking to areas that need not be enclosed and separately ventilated. Of the 174 towns that, at a minimum, restrict smoking to bar areas or separately ventilated areas (codes $2-7), 35(20.1 \%)$ allow variances. Overall, 60 towns, covering only $17.7 \%$ of the population, completely banned smoking in restaurants (including no variance allowances).

We examined the specific provisions regarding ESV areas to determine the extent to which towns limited the size of these areas, ensured that non-smokers do not have to pass through these areas, and ensured that minors would not be seated in these areas (table 2). Of the 64 towns restricting smoking to ESV areas, 24 (37.5\%) allowed smoking areas larger than 25\% of seating capacity and also allowed smoking areas to be

Table 2 Specific provisions for enclosed and separately ventilated smoking areas

\begin{tabular}{|c|c|c|}
\hline & $\begin{array}{l}\text { Frequency } \\
(n=64)\end{array}$ & $\begin{array}{l}\% \text { of } \\
\text { towns }\end{array}$ \\
\hline \multicolumn{3}{|l|}{ Size and pass through provisions } \\
\hline Size requirements ${ }^{*}$ met & 9 & 14 \\
\hline Pass through requirements $\dagger$ met & 23 & 36 \\
\hline Neither requirements met & 24 & 37.5 \\
\hline Both requirements met & 8 & 12.5 \\
\hline \multicolumn{3}{|l|}{ Minors in smoking areas } \\
\hline Minors excluded & 20 & 31.3 \\
\hline Minors allowed & 44 & 69.7 \\
\hline \multicolumn{3}{|c|}{$\begin{array}{l}\text { *Designated smoking area is no larger than } 25 \% \text { of the overall } \\
\text { seating capacity of the restaurant. } \\
\text { †Customers do not need to pass through a smoking area to reach } \\
\text { non-smoking seating. }\end{array}$} \\
\hline
\end{tabular}

located such that non-smokers may have to pass through to reach their seats; only eight towns $(12.5 \%)$ did not allow either. Forty four of these towns $(68.8 \%)$ allowed minors in the ESV smoking areas.

\section{Protection of restaurant customers and workers from secondhand smoke}

Despite the presence of 225 local restaurant smoking regulations in Massachusetts, $81.3 \%$ of adults and $81.4 \%$ of youths are not guaranteed protection from exposure to secondhand smoke in restaurants in their towns of residence (table 3). Using our assumption that the number of bar and restaurant workers in each town is proportional to the town population, our analysis shows that $82.3 \%$ of restaurant workers and $87.0 \%$ of bar workers are not guaranteed protection from secondhand smoke at work.

We compared our estimates of the population protected by local restaurant smoking regulations with previous reports. According to one previous report, ${ }^{22}$ as of 2000, 102 Massachusetts towns had complete restaurant smoking bans, covering $45 \%$ of the population; we found that as of 15 June 2002, 60 towns had regulations in effect that did not allow smoking in restaurants (including no variance allowances), covering $18 \%$ of the population. In another report, ${ }^{19} 32$ of 126 towns noted to have local restaurant smoking regulations were reported to have 100\% smoke-free restaurant regulations (including bar areas) as of 2000; we found that as of 15 June 2002, 17 of these

Table 3 Number of towns and percentage of the population covered by regulations that protect restaurant customers and workers

\begin{tabular}{llll}
\hline & $\begin{array}{l}\text { Number } \\
\text { of towns }\end{array}$ & $\begin{array}{l}\% \text { of } \\
\text { towns }\end{array}$ & $\begin{array}{l}\text { \% population } \\
\text { covered }\end{array}$ \\
\hline $\begin{array}{l}\text { Restaurant customers* } \\
\quad \begin{array}{l}\text { Adults } \\
\quad \text { Youth }\end{array}\end{array}$ & 71 & 20.2 & 18.7 \\
$\begin{array}{l}\text { Workers } \\
\quad \text { Restaurant workers }\end{array}$ & 65 & 18.5 & 18.6 \\
$\quad 60$ & 17.1 & 17.7 \\
$\quad$ Bar workers & 45 & 18.8 & 13 \\
\hline
\end{tabular}

*The percentage of restaurant customers protected from exposure to secondhand smoke based on the following criteria: the actual smoking restriction or prohibition, the size of designated smoking areas, and whether customers have to pass through a smoking area to reach nonsmoking seating.

tThe percentage of workers protected from exposure to secondhand smoke based on whether or not smoking is completely banned in the respective work places. 
126 towns had regulations in effect that did not allow smoking in restaurants. A third report ${ }^{20}$ listed that as of June 2002, 126 towns had $100 \%$ smoke-free restaurant regulations in effect; we found that as of 15 June 2002, 43 of these towns did not allow smoking in restaurants.

\section{DISCUSSION}

To the best of our knowledge, this is the first article to provide a detailed analysis of the specific provisions of local restaurant smoking regulations and to assess the degree to which existing regulations actually protect the public's health. This analysis advances the public health literature by: (1) increasing the understanding of the level of public health protection actually provided by local restaurant smoking regulations; (2) identifying specific provisions that weaken the public health impact of these regulations so to guide the development of more effective regulations in the future; and (3) operationalising the term "smoke-free" so that it becomes a meaningful concept in public health research and practice.

We found that although 225 of the 351 Massachusetts cities and towns had local smoking regulations in effect as of 15 June 2002, only 60 , covering $17.7 \%$ of the population, completely banned smoking in restaurants without exception, therefore guaranteeing protection from secondhand smoke for all restaurant customers and workers. Even fewer towns (45) had regulations that guaranteed protection from secondhand smoke for bar workers and customers, and these covered only $13.0 \%$ of the population. Thus, despite the widespread proliferation of local restaurant smoking regulations in Massachusetts, only a fraction of these policies actually provide adequate public health protection.

We determined that there were a number of reasons why many local regulations fall short in this regard. These include allowing smoking in designated areas that are not enclosed and separately ventilated; allowing smoking in ESV areas; allowing smoking in bar areas, whether or not they are enclosed and separately ventilated; allowing smoking in adult only restaurants; and allowing variances and exemptions that make it possible for restaurants to bypass the regulation. While regulations that restrict smoking to ESV areas may protect customers, they in no way protect workers who serve in these areas. In most cases, the regulations did not mandate the appropriate size to ensure the availability of non-smoking seating, did not ensure that non-smokers would not need to pass through these areas, and did not ensure that minors were excluded from these areas.

We found that a large number of towns with regulations that had in previous reports ${ }^{19} 2022$ been classified as having a "complete restaurant smoking ban" or as being "100\% smoke-free" in fact allowed smoking in restaurants. This discrepancy appears to be attributable to three factors: (1) classifying regulations that allow ESV smoking areas as complete restaurant smoking bans; (2) classifying towns as $100 \%$ smoke-free if they ban smoking in dining areas, regardless of whether smoking is allowed in the bar area; and (3) classifying regulations as complete smoking bans or as 100\% smokefree if they allow variances. Recently, Americans for Nonsmokers' Rights, one of the organisations reporting on the regulations, changed their coding system so that they now code regulations as " $100 \%$ smoke-free" only if they "do not allow smoking in attached bars or separately ventilated rooms and do not have size exemptions". ${ }^{33}$

In this paper, we classified regulations based on the extent to which they actually protect both restaurant workers and customers from exposure to secondhand smoke. Regulations that restrict smoking to ESV areas or to bar areas may in some cases protect restaurant customers, but do not protect restaurant workers. Thus, regulations that allow variances essentially enable smoking in restaurants, albeit under certain conditions. Hence, classifying these regulations as "smoke-free" may be misleading because it is entirely possible that neither workers nor customers are actually being protected.

These findings have a number of important public health policy implications. First, they suggest that efforts to protect the public from secondhand smoke exposure in restaurants and bars are not as advanced as was previously thought. Even in Massachusetts, which has the most local restaurant smoking regulations of any state in the country (other than California, which is covered by a state law), ${ }^{18}{ }^{20}$ less than a fifth of the population is protected from secondhand smoke exposure in restaurants.

Second, these findings suggest the need to re-evaluate the underlying purpose of smoke-free restaurant and bar regulations. In Massachusetts, the original aim of many restaurant smoking regulations appears to have been subsumed by the political and economic concerns that influence policy makers. As such, there are a large number of regulations, but only a small number that actually provide protection of the public's health. Even when the intent to protect persons from secondhand smoke seems to be present, our results suggest that most local "smoke-free" restaurant regulations are being adopted to reduce secondhand smoke exposure among restaurant patrons, but ignore the more significant effects on restaurant workers. $^{7}$

Third, our findings suggest the need to examine the role of public health officials in formulating policy regarding smoking in restaurants and bars. In the face of strong opposition to local regulations, policymakers are compromising the public's health by diluting regulations so much that they no longer actually provide substantive public health protection. This is particularly problematic given that most of the regulations in Massachusetts have been adopted not by city or town councils, but by boards of health, whose primary responsibility is to protect public health without undue influence by political or economic concerns. ${ }^{34}$

That boards of health have been remiss in upholding their primary responsibility in limiting exposure to secondhand smoke is demonstrated by comments of several board of health members. For example, the chairman of the Randolph Board of Health was quoted as saying: "The Board of Health feels (a total restaurant smoking ban) will be unfair to restaurants and private organizations." ${ }^{35}$ Regarding a smoking ban or strict smoking rules, the Lynn health director was reported as saying: “...I don't like the government interfering to the point where they're going to tell everyone what to do. What are we going to ban next?"36

Fourth, it appears that the concept of restricting smoking to ESV smoking areas, which in many cases has been supported by public health advocates, may be doing more harm than good. The availability of this compromise may give policymakers a "false sense of security"; but this is being accomplished in a manner that, in fact, compromises the public's health by continuing to expose restaurant workers, in particular, to dangerous levels of secondhand smoke. Moreover, creating separately ventilated areas is expensive for restaurant owners and, if policy makers wish to strengthen the regulation at a later time, restaurant owners may argue that this is unfair because of the prior economic burden of having to create these areas. ${ }^{37}$ In fact, we found few examples where ESV area regulations were strengthened to eliminate smoking completely in restaurants. According to our database, of the 38 regulations effective between 1 January 2001 and 15 June 2002 that eliminated smoking in restaurants (codes 6 and 7), only two represented cases in which a regulation restricting smoking to ESV areas (codes 3 and 4) was strengthened.

These findings also have an important implication for surveillance efforts and future research. In previous research, the connection between the classification of restaurant smoking regulations and the broader public health context has been unclear. Previous classifications of restaurant smoking regulations have not been conceptually tied to the actual public 
health protection provided by the regulations. Our findings suggest that significant variability exists in what is considered a restaurant smoking ban. Such discrepancies in understanding the practical meaning of regulations may result from the absence of a common definition of regulation terms and a specific description of regulation provisions.

While this study was conducted using only Massachusetts regulations, we reviewed other states' regulations and found that the ways in which the regulations are constructed are similar across states, including the nature of exceptions and exemptions. These findings are therefore generalisable to other states and serve a twofold purpose: (1) to help public health advocates around the country assess the current state of regulations and to help determine what the loopholes are to ascertain what protection from secondhand smoke exposure is actually being provided; and (2) to help practitioners analyse regulations within a framework that examines regulations in terms of protection offered to certain groups. This surveillance system can be implemented in every state using minimal resources and should be made a standard part of public health practice.

There are two important limitations of our analysis. First, our conclusions are based on the provisions of such regulations, not the implementation of the regulations in actual practice. For example, the fact that a regulation permits smoking in separately ventilated areas does not necessarily mean that restaurants will choose to create such areas; restaurants may decide to eliminate smoking entirely, rather than to build these areas. Similarly, the availability of a variance from a regulation does not necessarily mean that restaurants will apply for and obtain such a variance. However, given the vigorous opposition of many restaurant owners to smoking regulations, it is to be expected that when given the opportunity to accommodate smoking in their establishments, many proprietors will do so.

Second, this paper does not assess actual compliance with, and enforcement of, the regulations. It is possible that even in towns that completely ban smoking in restaurants, noncompliance may effectively undermine protection from secondhand smoke. However, several studies have demonstrated high levels of compliance with restaurant ${ }^{38-45}$ smoking restrictions.

Despite these limitations, our analysis demonstrates that even in a state with 225 local restaurant smoking regulations - the second most of any state-there is still a long way to go in protecting the public from secondhand smoke exposure in restaurants and bars. And, although boards of health have been willing to address the issue of smoking in restaurants, many have failed to uphold their primary responsibility to protect citizens from a known and deadly carcinogen by diluting the regulations in response to political and economic pressures in a way that explicitly compromises protection of the public's health. In addition, the regulations have largely ignored the protection of restaurant and bar workers, who are most affected by exposure to secondhand smoke.

To address these problems, we contend that public health practitioners must re-focus on the original purpose of restaurant smoking regulations. They must stop compromising and accept nothing short of policies that adequately protect the public, including workers, from the hazards of secondhand smoke exposure. Public health advocates should avoid or overhaul regulations that allow separately ventilated smoking areas, which fail to protect restaurant workers, pose increased risks for customers and workers in those areas, and are difficult to strengthen. Furthermore, researchers and practitioners need to use a common definition of smoke-free restaurant regulations. We suggest that this term be limited to regulations that eliminate smoking in restaurants without exception. Ultimately, continuing to compromise the public's health by promoting or accepting regulations that allow

\section{What this paper adds}

While a number of reports have described the prevalence and nature of local restaurant smoking regulations, until now, none have provided a comprehensive analysis of all the provisions of each regulation and an assessment of how the totality of each regulation, interpreted in its entirety, relates to the degree of actual protection from secondhand smoke that the regulation guarantees. We therefore presently have very little understanding of the level of public health protection that is afforded by these policies.

This analysis increases the understanding of the level of public health protection actually provided by local restaurant smoking regulations, identifies specific provisions that weaken the public health impact of these regulations and, in essence, operationalises the term "smoke-free" so that it becomes a meaningful concept in public health research and practice.

customers or workers to be exposed to a deadly carcinogen cannot be justified.

\section{ACKNOWLEDGEMENTS}

This work was supported by grants from the National Cancer Institute, State and Community Tobacco Control Interventions Research Grant Program (grant number 5 R01 CA86257-03) and the Flight Attendant Medical Research Institute.

\section{Authors' affiliations}

M Skeer, M Siegel, Boston University School of Public Health, Social and Behavioral Sciences Department, Boston, Massachusetts, USA

\section{REFERENCES}

1 California Environmental Protection Agency. Health effects of exposure to environmental tobacco smoke: final report. Berkeley, California: California Environmental Protection Agency, Office of Environmental Health Hazard Assessment, September 1997.

2 US Environmental Protection Agency. Respiratory health effects of passive smoking: lung cancer and other disorders. Washington DC: US Environmental Protection Agency, Office of Research and Development, Office of Air and Radiation, 1992.

3 US Department of Health and Human Services. Ninth report on carcinogens. Washington DC: Public Health Service, National Toxicology Program, 2001

4 Glantz SA, Parmley WW. Passive smoking and heart disease: epidemiology, physiology, and biochemistry. Circulation 1991;83:1-12.

5 Gerlach KK, Shopland DR, Hartman AM, et al. Workplace smoking policies in the United States: results from a national survey of more than 100000 workers. Tobacco Control 1997;6:199-206.

6 National Cancer Institute. State and local legislative action to reduce tobacco use. Smoking and Tobacco Control Monograph No. 11. Bethesda, Maryland: US Department of Health and Human Services, National Institutes of Health, National Cancer Institute; August 2000

7 Siegel $\mathbf{M}$. Involuntary smoking in the restaurant workplace: a review of employee exposure and health effects. JAMA 1993;270:490-3.

8 Jenkins RA, Counts RW. Occupational exposure to environmental tobacco smoke: results of two personal exposure studies. Environ Health Perspect 1999;107(suppl 2):341-8.

9 Hammond SK. Exposure of U.S. workers to environmental tobacco smoke. Environ Health Perspect 1999;107(suppl 2):329-340.

10 Wortley PM, Caraballo RS, Pederson LL, et al. Exposure to secondhand smoke in the workplace: serum Cotinine by occupation. J Occup Environ Med 2002;44:503-9.

11 Miesner EA, Rudnick SN, Hu FC, et al. Particulate and nicotine sampling in public facilities and offices. Journal of the Air Pollution Control Association 1989;39:1577-82.

12 Jarvis MJ, Foulds J, Feyerabend C. Exposure to passive smoking among bar staff. Br J Addiction 1992;87:111-13.

13 Maskarinec MP, Jenkins RA, Counts RW, et al. Determination of exposure to environmental tobacco smoke in restaurant and tavern workers in one US city. Journal of Exposure Analysis and Environmental Epidemiology 2000; 10:36-49

14 Ott W, Switzer P, Robinson J. Particle concentrations inside a tavern before and after prohibition of smoking: evaluating the performance of an indoor air quality model. J Air Waste Manage Assoc 1996;46:1120-34. 
15 Besaratinia A, Maas LM, Brouwer EMC et al. A molecular dosimetry approach to assess human exposure to environmental tobacco smoke in pubs. Carcinogenesis 2002;23:1171-6.

16 Siegel $M$, Carol J, Jordan J, et al. Preemption in tobacco control. JAMA 1997:278:858-63.

17 Jacobson PD, Zapawa LM. Clean indoor air restrictions: progress and promise. In: Rabin RL, Sugarman SD, eds. Regulating tobacco. New York: Oxford University Press, 2001

18 Siegel $\mathbf{M}$. The effectiveness of state-level tobacco control interventions: a review of program implementation and behavioral outcomes. Annu Rev Public Health 2002; 23:45-71.

19 National Cancer Institute. State and local legislative action to reduce tobacco use. Smoking and Tobacco Control Monograph No 11 Bethesda, Maryland: US Department of Health and Human Services, National Institutes of Health, National Cancer Institute, 2000. (NIH Publication No. 00-4804.

20 American Nonsmokers' Rights Foundation. 100\% smokefree ordinances. 31 May 2002. Accessed 25 June 2002. URL: http://no-smoke.org/100ordlist.pdf

21 US Department of Health and Human Services. Preventing tobacco use among young people. A report of the Surgeon General, 1994. Atlanta, Georgia: Public Health Service, Centers for Disease Control and Prevention, Office on Smoking and Health, 1994. (US Government Printing Office Publication No S/N 017-001-00491-0.)

22 Abt Associates Inc. Independent evaluation of the Massachusetts Tobacco Control Program: seventh annual report. Cambridge, Massachusetts: Abt Associates Inc, 2001

23 Chriqui JF, Frosh M, Brownson RC, et al. Application of a rating system to state clean indoor air laws (USA). Tobacco Control 2002;11:26-34.

24 US Census Bureau. Census 2000, Summary File 3. US Department of Commerce, 27 August 2002.

25 Lewit EM, Hyland A, Kerrebrock N, et al. Price, public policy, and smoking in young people. Tobacco Control 1997;6(suppl 2):S17-24.

26 Bartosch WJ, Pope GC. The economic effect of smoke-free restaurant policies on restaurant business in Massachusetts. Public Health Management Practice 1999;5:53-62.

27 Bartosch WJ, Pope GC. Local enactment of tobacco control policies in Massachusetts. Am J Public Health 2002;92:941-3.

28 Bartosch WJ, Pope GC. Local restaurant smoking policy enactment in Massachusetts. Public Health Management Practice 1999:5:63-72.

29 Klonoff EA, Landrine H, Alcaraz R, et al. An instrument for assessing the quality of tobacco-control policies: the ACT-L scale. Prev Med 1998;27:808-14.
30 Brownson RC, Eriksen MP, Davis RM, et al. Environmental tobacco smoke: health effects and policies to reduce exposure. Annu Rev Public Health 1997; 18:163-85.

31 Massachusetts Department of Public Health. Enacted local ETS measures in restaurants and bars. Boston, Massachusetts: Massachusetts Department of Public Health, April 2002.

32 Repace JL. Risk management of passive smoking at work and at home. St Louis University Public Law Review XIII. 1994;2:763-85.

33 American Nonsmokers' Rights Foundation. 100\% smokefree ordinances. 9 December 2002. Accessed 16 January 2003. URL: http://no-smoke.org/100ordlist.pdf

34 Dearlove JV, Glantz SA. Boards of health as venues for clean indoor air policy making. Am J Public Health 2002;92:257-65.

35 Barry J. Randolph town meeting rejects smoking ban. The Enterprise 21 June 2002

36 Laidler J. Where the puffers roam free. Boston Globe. 12 January 2003.

37 Paradise JR. Plymouth's ban on smoking stays: most voters opposed to repeal. The Patriot Ledger. 13 May 2002.

38 Ying JYC, Abernathy T, Choi BCK. A comprehensive evaluation of the 1993 City of Toronto smoking by-laws. Can J Public Health 1995;86:32-6.

39 Stanwick RS, Thomson MP, Swerhone PM et al. The response of Winnipeg retail shops and restaurants to a bylaw regulating smoking in public places. Can J Public Health 1988;79:226-30.

40 Chapman S, Borland R, Lal A. Has the ban on smoking in New South Wales restaurants worked? A comparison of restaurants in Sydney and Melbourne. Med J Aust 2001;174:512-15.

41 Cheadle AD, Psaty BM, Curry S, et al. Assessing the validity of a survey of the restaurant health promotion environment. Am J Health Promotion 1994;9:88-91.

42 Hyland A, Cummings KM, Wilson MP. Compliance with the New York City Smoke-Free Air Act. J Public Health Manage Pract 1999;5:43-52.

43 Magzamen S, Glantz SA. The new battleground: California's experience with smoke-free bars. Am J Public Health 2001:91:245-52.

44 Kagan RA, Skolnick JH. Banning smoking: compliance without enforcement. In: Rabin RL, Sugarman SD. Smoking policy: law, politics, and culture. New York: Oxford University Press, 1993:69-94.

45 Miller C, Wakefield M, Kriven S, et al. Evaluation of smoke-free dining in South Australia: support and compliance among the community and restaurateurs. Aust N Z J Public Health 2002;26:38-44.

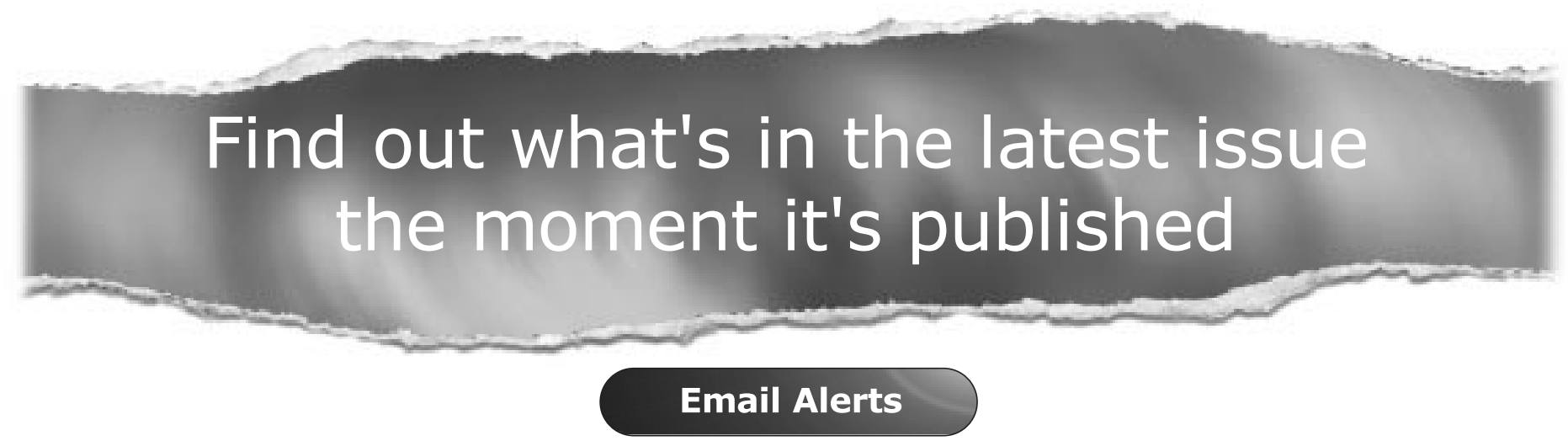

Sign up to receive the table of contents by email every month. You can select from three alerts: Table of Contents (full), TOC Awareness (notice only); Tobacco Control related announcements.

www.tobaccocontrol.com 